\section{A comunicação sem fim (teoria pós-moderna da comunicação)}

\section{RESUMO}

Neste artigo Maffesoli ressalta a importância da comunicação como cimento social e as suas implicações no mundo contemporâneo.

\begin{abstract}
In this paper the author emphasises the importance of communication as a social cement and its implications to our times.
\end{abstract}

PALAVRAS-CHAVE (KEY WORDS)

- Imaginário (Imaginary)

- Mídia (Media)

- Socialidade (Sociality)

\section{Michel Maffesoli}

Sorbonne, Paris V/França
Comunicação é um termo que raro emprego, embora reconheça cada vez mais a sua pertinência. Trata-se da maneira contemporânea, pós-moderna, de fazer referência ao simbolismo (não no sentido simples do termo, simbólico, mas na acepção freudiana e lacaniana de simbolismo). Não seria errado também falar em comunicação por referência aos novos pensamentos místicos, caso se tome por essencial a idéia de conjunção: a comunicação é que nos liga ao outro. Para usar o meu vocabulário habitual, a comunicação é o que faz reliance (religação). A comunicação é cimento social.

Talvez eu fale tão pouco de comunicação porque para mim essa noção está implícita na socialidade. A comunicação é a cola do mundo pós-moderno. Dito de outra forma, a comunicação é uma forma de reencarnação desse velho simbolismo, simbolismo arcaico, pelo qual percebemos que não podemos nos compreender individualmente, mas que só podemos existir e compreendermo-nos na relação com o outro. Nesse sentido, a idéia de individualismo não faz muito sentido, pois cada um está ligado a outro pela mediação da comunicação. O importante é o primum relationis, ou seja, o princípio de relação que me une ao outro.

Qual é o fundamento de tudo isso? Até agora, na tradição cultural da modernidade, prevaleceu a lógica de fazer a História e, de acordo com o imaginário do século XIX, só se faz História quando se é capaz e fazer a sua própria história, na condição e isolamento, por assim dizer, de senhor de si. Ora, na idéia de comunicação, como na de simbolismo, há encontro. E só pode haver encontro 
quando se participa de um destino comum. Heidegger concebeu uma bela fórmula para sintetizar tudo isso: "Compreender é vibrar". As conseqüências epistemológicas, de conhecimento, dessa idéia são enormes. Compreender, no sentido etimológico da palavra, significa pegar com, tomar junto, reunir, abordar o mundo na sua totalidade, abrir-se aos outros. Essa forma de vibração remete essencialmente à comunicação. A palavra comunicação serve também para encarnar o retorno dessa velha idéia que é o imaginário, ou seja, o fato de que se vibra com outros, em torno de alguma coisa, seja qual for essa coisa.

Não se deve cair em fetiches conceituais, mas é possível precisar certas palavras ou, ao menos, tentar encontrar termos mais adequados para expressar situações realmente vividas. Comunicação e informação são etiquetas em voga. Ambas expressam conteúdos importantes da época atual. Caso se dê à palavra informação o seu verdadeiro sentido etimológico - dar forma -, não haveria diferença entre informação e comunicação. Informar significa ser formado por. Tratase da forma que forma, a forma formante. Quer dizer que numa era da informação, talvez a de hoje, não se pensa por si mesmo, mas se é pensado, formado, inserido numa comunidade de destino. Vale repetir: a forma é formante. A informação também liga, une, junta.

A comunicação põe em relação, primum relationis, o que remete para essa sociedade da informação, pela qual se é formado num mundo comum, onde o indivíduo só é o que é na relação com outras pessoas. O grande problema é o monopólio das palavras informação e comunicação pela intelligentsia, os intelectuais hegemônicos, que não presta atenção ao sentido profundo desses termos. Assim, fala-se de informação sem pensar no que significa pôr em forma; e fala-se de comunicação sem referência à criação desse destino comum. O essencial é deixado de lado. Desaparece o elemento participativo, a partilha, o laço social.

$O$ fato de que essas palavras se imponham, contra os que as utilizam e controlam, é um indício, um sintoma, de algo importante: a prevalência do vivido em relação aos protagonistas do terreno intelectual. $\mathrm{Na}$ verdade, os intelectuais moralistas e politicamente corretos são obrigados a utilizar esses termos, pois o espírito do tempo está na forma comum, impregna esse comportamento relacional e estabelece um modo de vida. Comunicação e informação descrevem um modus vivendi característico da pós-modernidade. Cabe empregar tais elementos pertinentes de descrição do real, mas com astúcia, subvertendo as palavras, transfigurando a forma banalizada, superficial, em benefício do sentido profundo, com a convicção de que se algumas fórmulas se disseminam no tecido social é por encontrarem substância no existente. Nesse sentido, elas nunca são neutras. No caso, exprimem o desejo de estar com outro, desejo de participação, de interação e de troca.

Estabelecida essa linha de continuidade entre comunicação e informação, nuanças são possíveis. A comunicação, antes de tudo, remete ao estar-junto; à informação, ao utilitário. O essencial, contudo, reside no oposto, na ausência de diferença profunda entre informação e comunicação, contrariando as noções dominantes em certos meios e entre muitos dos ditos especialistas do tema. Há redundância na expressão informação e comunicação ou comunicação e informação. Mesmo que o termo informação seja instrumentalizado, tornando-se alvo de críticas, há todo um substrato, uma potência "societal" que força, em determinado momento, uma concepção ou termo a ocupar novamente o centro da cena, o primeiro plano no palco das práticas sociais. A potência, ao contrário do poder que é instituído ou forma de controle, corrói subterraneamente as estruturas calcificadas e expressa um modo anárquico do social. Trata-se de uma 
resistência permanente.

Mesmo, portanto, que a informação seja apropriada e instrumentalizada temporariamente, a potência subterrânea tende a impor a força comunicativa (relacional) dessa informação, ou seja, a capacidade de estabelecer comunhão e partilha de algo entre indivíduos e grupos. Como se diz no jargão da sociologia da comunicação, a emissão não pode controlar efetivamente a recepção. A instrumentalização da informação aconteceria se essa informação fosse total, global, capaz de dar nova substância ao velho fantasma do universalismo. Ora, na prática, a informação só consegue unir microgrupos, microcosmos, universos segmentados.

No Brasil, muito mais ainda que na França, os jornais (informação) seduzem microgrupos. Primeiro são jornais regionais. Mesmo os de alcance nacional, como Folha de S. Paulo, O Estado de S. Paulo, O Globo e Jornal do Brasil, conservam marcas de inserção regional muito fortes. O Jornal do Brasil e O Globo encarnam, até certo ponto, um espírito carioca. Folha de $\mathrm{S}$. Paulo e $\mathrm{O}$ Estado de São Paulo expressam, como se diz, principalmente os interesses paulistas ou, ao menos, um modo de ver, um estilo dito paulista. Depois, dentro de cada jornal, as diferentes seções conquistam públicos específicos. Raramente a informação alcança todos ao mesmo tempo. Quase nunca ela é universal. Esse é um mito do jornalismo ocidental.

No fundo, o leitor interessa-se pelo que the diz respeito. Não por acaso, surgem cadernos de bairro, edições regionais de revistas nacionais e coberturas mais intensas das ações de figuras locais. Numa Olimpíada, cada jornal quer cobrir os feitos do "herói" local. Para além das qualidades esportivas do competidor, a sua principal qualidade é a de ser o representante de uma cidade, de um país, de uma comunidade, de uma aldeia. Mais do que ver a gente quer se ver na tevê. Todo mundo sabe disso.
No interior do quadro geral (informação), disseminado por um suporte técnico (jornal, veículo), abrigam-se os imaginários locais. Zero Hora e Correio do Povo, Tribuna do Norte e A Tarde, entre outros que acompanho em minhas viagens constantes ao Brasil, articulam o abstrato (informação global) com o substantivo (o vivido local). Aniversários, casamentos, fofocas de celebridades, mas também de notáveis locais, seções chamadas "Gente" e tantas outras desse gênero, continuam a conviver com o pretenso racionalismo utilitário da informação.

Por mais que isso horrorize os críticos politicamente corretos, as pessoas não querem só informação na mídia, mas também e fundamentalmente ver-se, ouvirse, participar, contar o próprio cotidiano para si mesmas e para aqueles com quem convivem. A informação serve de cimento social. Mais do que saber se Bush vai ou não invadir o Iraque, um leitor, um ouvinte, um telespectador distante da área desse conflito quer saber, com freqüência, de coisas muito menos sérias, mas não menos importantes para a coesão social. Os jornalistas gostam de imaginar o contrário e de ver-se como protagonistas de grandes aventuras. O leitor está louco para saber o final da novela ou como foi tal festa num clube da moda. A sociedade da informação, portanto, pode até fazer crer que o mais importante são os seus jornais, televisões e rádios, mas no fundo o que conta é a partilha cotidiana e segmentada de emoções e de pequenos acontecimentos. Mesmo na internet o aspecto interativo predomina sobre o utilitário. De alguma forma, o mais interessante é o grau zero da informação.

Nisso tudo, claro, há informação. No entanto, o essencial está em reconhecerse, em ver-se, em fazer parte de uma comunidade presencial ou virtual. Há sempre muito de espetáculo e de fait divers na informação. Na França, relativizados os jornais nacionais, Le Figaro, Le Monde, Libération, etc., vê-se a mesma 
coisa. Em jornais como Midi Libre, Les Dernières Nouvelles d'Alsace, etc., o que realmente importa são as páginas regionais. Interessante é que essas páginas entram num sanduíche, entre a capa e a contracapa dedicadas aos temas mundiais. Na primeira página aparecem as grandes manchetes internacionais. $\mathrm{Na}$ última, especialistas comentam os assuntos da primeira. O nível de leitura de ambas é ínfimo. Não são lidas. Num sanduíche, como se sabe, o que realmente alimenta está dentro, entre duas camadas menos nutritivas. Nas parte de fora; predomina a obsessão política; dentro, tudo aquilo que faz a vida de todos os dias e de todas as pessoas. Nisso, evidentemente, há informação no sentido etimológico já indicado aqui. O público absorve, do conjunto das informações, aquilo que faz vibrar e estabelece comunidade. A informação é qualificada em função da sua capacidade de gerar proxemia.

A comunicação é cada vez mais segmentada, dirigida a um público-alvo. De qualquer maneira, os interessados, ainda que teorizem sobre isso, não possuem os instrumentos teóricos para pensar os seus alvos. Conseguem esboçá-los para oferecer produtos, mas não percebem que algo escapa, justamente a dimensão pósmoderna do fenômeno, o aspecto tribal. A informação e a comunicação, no sentido da partilha de emoções e de sentimentos, só podem dirigir-se a tribos que comungam em torno de um totem. A comunicação, portanto, é forma contemporânea de exprimir essa velha forma arquetípica de comunhão em torno de um totem. Em qualquer forma de comunicação e de informação há essa possibilidade de criação, em dado momento, de um totem, seja pelas lembranças de família, pelo desejo de criação de um grupo a partir de um elemento comum, por exemplo, a identificação sexual. Existem jornais dirigidos à comunidade homossexual que, para além das informações veiculadas, oferecem um ponto de encontro, uma referência, um elemento de identificação, um totem em torno do qual comungam esses homossexuais. No caso, há segmentação, mas o fator de relação entre os integrantes desse público-alvo e o veículo é de ordem emocional.

Os cursos de Comunicação, em países como o Brasil, são importantes, entre outras coisas, pelo fato que permitem uma reflexão diferenciada e prospectiva sobre um tema que em outros departamentos está comprometido pelos vícios da ideologia e da obsessão política. Em lógica, quando se observa que uma determinada forma ganha importância, essa forma tem uma lógica de modalidade. A modalidade é uma espécie de pequeno afastamento em relação a uma forma geral. Mas ela só existe na relação com essa forma geral. Comunicação e informação não passam de modalidades de uma mesma forma global, a da relação, do estar-junto, do contato social. A partir daí são possíveis muitos tipos de pesquisa de campo dando conta dos vários aspectos e das várias práticas em torno do par comunicação/informação.

Novas palavras surgem para rotular velhas práticas ou velhas palavras são ressignificadas para caracterizar a nova força de práticas sempre existentes. Comunicação e informação dão nova potência a um dos mais sólidos arcaísmos: estar em relação. Mesmo se agora se trata de relações mediadas tecnologicamente. As ditas ciências da comunicação e da informação têm dificuldade para pensar o mundo sensível e compreender essa vibração em comum. Prefere-se então focalizar coisas aparentemente mais objetivas, deixando-se de lado o cerne da questão: o que comunicar quer dizer? Estar junto, estar em relação, estar em vibração comum.

Continua a existir uma imensa dificuldade de pensar sensitivamente, incluindo a parte sensível da vida. A vida social baseia-se quase inteiramente na atração e na repulsão. Vibra-se em 
comunicação com alguns, obtendo-se também nesse processo informações, e não com outros. As relações de empatia são decisivas na estruturação do tecido social. Essa vibração - real, presencial, fantasiosa ou virtual - ultrapassa qualquer conteúdo, pois, antes de tudo, é forma. A informação é também modalidade do continente. $\mathrm{Na}$ verdade, a complexidade dos fenômenos sociais exige uma leitura capaz de integrar o contraditorial. Cidades como México ou São Paulo parecem inabitáveis. Em princípio, não daria para viver nelas. No entanto, há muita vida nelas. Pode-se sentir medo e concluir que não pode dar certo. Contudo, com suas lógicas próprias, há vida, atração e mesmo paixão por essas cidades. Elas permanecem lugares de encontro e de convivência. Isso tudo ultrapassa o terreno das idéias e mostra-se como tal: expressões concretas da comunicação.

A comunicação e a informação dão nova substância a essa função comunitária, contra ou em paralelo ao que dizem os teóricos da comunicação mais convencionais, ou seja, os que denunciam constantemente o caráter anti-social da mídia. Para além de uma opinião pública que a informação deve atingir, as teorias da comunicação nem sempre têm a coragem de estudar e de considerar as emoções suscitadas. O gosto atual, intenso, pelas imagens pode levar a estabelecer o laço entre comunicação, informação e imaginário. Vale tentar: o imaginário é a partilha, com outros, de um pedacinho do mundo. A imagem não passa disso: um fragmento do mundo. A informação serve, então, para fornecer elementos de organização do puzzle de imagens dispersas. Assim, as tribos de cada cultura, partilhando pequenas emoções e imagens, organizam um discurso dentro do grande mosaico mundial.

Nesse sentido, o universalismo cede lugar às apropriações particulares do global. As teorias e idéias são redimensionadas pelo concreto da vida cotidiana, pelas vivências de pequenas comunidades. Nisso tudo, entram motivações utilitárias, práticas, intelectuais, mas também lúdicas, oníricas, que se esgotam em si mesmas. A comunicação pode ser, como nas conversas sem razão de ser de todo dia, um ato em si: conversar por conversar, para estar junto, para passar o tempo, para dividir um sentimento, uma emoção, um momento, um pequeno nada de cada dia. Comunicar por comunicar.

A informação pode até ser vista como uma astúcia da comunicação. A pessoa olha um telejornal, em princípio para informarse, mas, em realidade, toma-o como um espetáculo, um divertimento, um jogo de imagens. Depois, comenta os assuntos com amigos. A informação talvez nada tenha mudado em sua vida ou não tenha tido, para essa pessoa, nenhum valor efetivo, operacional, mas serviu de elo, de motivo para estar com outro, de assunto, de laço social. A maneira pela qual se lê um livro, como se aprende nas escolas, subentende uma linearidade, uma continuidade e até mesmo notas e reflexões. Na prática, as leituras são fragmentadoras, aos saltos, seletivas. Conta mesmo é descobrir, no conjunto, uma idéia sedutora, algo que faça sonhar, refletir, questionar-se. O fato de ter começado a sonhar a partir de uma frase (mesmo se as páginas anterior e posterior não me chamaram a atenção) me põe em relação com outros sonhos. Cria-se uma comunidade de espírito.

O mesmo vale para o universo da mídia. Os jornais, as emissoras de rádio, a televisão, internet, todos fornecem torrentes de material, mas cada um absorve algo, um fragmento que faz sonhar, estabelecendose uma comunidade espiritual, um grupo virtual de afinidades. Certas cenas tocam o coração, atingem o estômago, provocam reação. Essa vibração, mais uma vez, cria comunidade. Como se sabe, os programas de televisão fornecem (agendam) os assuntos da manhã seguinte nos pátios das escolas, nos escritórios e por toda parte. Cada um poderá dizer o que bem 
entender, fazer comentários contra ou a favor. Apenas os assuntos estão sugeridos. No dia seguinte, serão outros.

Mesmo no jornal Le Monde, talvez o mais sério e intelectualizado da imprensa francesa, a seção mais lida é a dos necrológios. Por quê? No fundo, por uma razão simples: estar em dia com o fluxo da vida. À mesa, o assunto será "fulano morreu". Ainda mais que num jornal como Le Monde são publicadas as notícias de morte de pessoas que integram um certo círculo social, por exemplo, os intelectuais, os políticos, os professores universitários, etc. É verdade que muitos intelectuais lêem isso quase em segredo, como se fosse pornográfico. Só que tem lógica nisso. Trata-se de espiar pela fechadura, colocar o nariz na vida, sujar as mãos. Conclusão: mesmo os veículos mais universalistas e os atores sociais mais interessados numa lógica abstrata, em tese, não resistem ao concreto da existência. Diante de uma notícia de morte, haverá quem chore, quem se alegre com o desaparecimento de um inimigo, quem se surpreenda.

Para que serve, então, a comunicação? Tradicionalmente, as chamadas funções da comunicação estabelecem uma hierarquia que vai da informação à distração, passando pela formação, pela educação, pela prestação de serviços ao público e outras categorias "nobres". Mesmo correndo o risco de provocar escândalo, ou de ser perverso, cabe dizer que a principal função da comunicação é divertir, distrair, entreter. Nisso, contudo, nada entra de pejorativo. Quando se fala em entretenimento, de maneira geral, pensa-se em subcultura, em consumidores inconscientes, manipulados e acríticos. No sentido pascaliano do termo, divertimento significa aquilo que se opõe à angústia da morte. $\mathrm{O}$ jansenista e moralista Pascal, vale lembrar, é o fundamento maior dos pensadores modernos.

Divertir-se significa pôr a morte de lado. Pascal diz que o divertimento tem também uma função ética. Ao passar ao lado da angústia da morte, que obceca, cria-se comunidade e vida fértil. Essa concepção leva a sair da idéia de história linear da qual cada um seria o condutor e a entrar na noção espiralada de pequenos passos, sujeitos a recuo ou a desvio, dados em conjunto, em associação com outros. A comunicação é divertimento, pois permite constituir as comunidades que fertilizam a vida e fazem esquecer provisoriamente a morte.

Existem coisas que não podem ser ditas e outras que suscitam discursos repetitivos, grandiloqüentes e vazios. Em relação à comunicação, conforme uma herança iluminista, é preciso sempre falar em educar o povo, formar os espíritos, dar cultura a todos, forjar verdadeiros cidadãos e por aí afora. Disfarça-se o divertimento, o entretenimento, com uma série de nomes e de causas grandiosas. Nada mais do que racionalizações. Hoje, embora o termo seja um tanto pomposo, deve-se "desconstruir" os mitos da teoria crítica da comunicação. À maneira de Nietzsche, cabe "suspeitar" das categorias que integram a comunicação a uma visão iluminista, progressista, linear, pedagógica e simplesmente utilitária.

Pesquisar, refletir, estudar, tudo isso implica a coragem e a liberdade de espírito para questionar as verdades dominantes. Comunicação é divertimento, inclusive no que se refere, muitas vezes, ao sério leitor do jornal Le Monde que espia os necrológios e sente-se contente por não ser ele o morto. Claro que existem outros aspectos. Porém não há razão suficiente para torná-los mais importantes do que o entretenimento. Pode haver uma caricatura nisso, mas não mais do que na transformação da comunicação em professor universal, em formador das boas consciências e um pastor das boas almas.

Fenômenos de mídia, como Big Brother, remetem ao mesmo tipo de análise. Na França, os intelectuais disseram milhões de bobagens contra o que seria mais uma forma de imbecilizar o povo. Combateu-se a "telerrealidade" como se ela 
não nos encarnasse, não nos mostrasse em nossas atitudes ridículas e obsessivas. Os jovens olharam esse programa, não necessariamente querendo estar lá, pois havia algo de prisão naquilo tudo, mas mobilizados seja por um processo de vacinação, seja por uma atração mesclada com repúdio. Ou simplesmente fascinados.

$\mathrm{Na}$ palavra divertimento há sempre uma dimensão judicativa: não é bom. O julgamento, dito crítico, marxista, neomarxista, coisas desse tipo, insiste sobre o tema da alienação. Divertir seria uma forma de imbecilizar as pessoas para dominá-las. Certas palavras, como alienação, estão fora de moda, mas a idéia persiste. Em A Conquista do presente, abordei o que continua sendo minha idéia fundamental: a astúcia. Faz de conta que... Como se... Já Schopenhauer trata dessa habilidade de fazer com que uma parte de si mesmo se comporte como tendo aderido a algo enquanto outra parte resiste.

O analista "crítico" só enxerga a manipulação e alienação onde há também resistência e reserva silenciosa. Às vezes, o indivíduo simula uma adesão ou não mostra interesse em opor-se a algo, mas no seu íntimo permanece refratário ou inalcançável. Pode-se não gostar de algo, mas se preferir, para não provocar choques de opinião, guardar um silêncio respeitoso e polido. Na vida social, com freqüência, as pessoas fazem de conta que são alienadas, embora, no íntimo, permaneçam atentas, reservadas, desconfiadas. Isso é válido para todos, inclusive para as pessoas mais simples. Trata-se de uma postura, não necessariamente consciente, racionalizada ou refletida.

As críticas da mídia baseadas na teoria da manipulação não percebem esse distanciamento, essa resistência passiva, essa astúcia do popular contra as intenções do poder. Os fins quase nunca são atingidos através do conteúdo. As mensagens políticas recorrem cada vez mais à forma, à publicidade, para terem eficácia. A manipulação, no fundo, é uma projeção, é o que os moralistas, sempre prontos a dar lições, gostariam de fazer, ou seja, controlar uma emissão poderosa e eficaz, apta a surtir efeito seguro sobre uma recepção passiva. Felizmente o mundo não funciona assim. O jornalista tornou-se o principal herdeiro dessa visão de mundo que enfatiza o poder da emissão.

Num artigo publicado no Figaro, sob o título de "O tempo do desprezo", refleti sobre o que aconteceu na França em 21 de abril de 2002, quando, no primeiro turno das eleições presidenciais, o primeiro-ministro Lionel Jospin, para surpresa geral, mesmo das pesquisas de opinião, perdeu a vaga no segundo turno para a extrema direita de Jean-Marie Le Pen. Jospin sempre fez o papel do puritano, do jansenista, do dono da verdade. A catástrofe consistia em descobrir que o povo não compreendeu o bem que Jospin podia fazer por ele. Longe de mim a idéia de apoiar Le Pen, mas, de qualquer maneira, havia algo interessante na atitude do eleitor - esse eleitor considerado incapaz de surpresas, manipulado, domesticado e morno - , uma espécie de piada de mau gosto, remetendo ao segundo turno o sujeito grosseiro, reacionário, caricatural, bufão... Na medida em que havia um segundo turno, logo uma possibilidade de evitar a eleição de Le Pen, o gesto funcionou como um tapa na cara dos políticos, uma reserva, perigosa, claro, de atitude da população contra a crescente ausência de distinção entre direita e esquerda.

Houve nisso uma astúcia do povo. Afora os eleitores de fato de extrema direita, aconteceu uma utilização de Le Pen pelo povo, sem qualquer adesão às suas idéias racistas e xenófobas, para dar um susto nas elites políticas pretensiosas e arrogantes. Contra as metralhadoras da mídia, que nunca pararam de falar do bom senso e do equilíbrio, os eleitores permitiram-se exprimir, emocional e perigosamente, mas no limite, a cólera acumulada ao longo dos anos. Essa atitude é semelhante à do garoto que, saturado 
dos discursos e dos sermões do professor, faz uma grande besteira, com a qual não concorda, da qual tem consciência, mas que the permite mostrar autonomia. Dado que não pode impor a sua vontade, manifesta-se ruidosamente. Situação típica. Histórica.

Há no povo uma vitalidade que escapa às teorias elitistas e abstratas. É isso que permite compreender como um candidato de esquerda ganha uma eleição depois que seu partido e seus militantes sempre disseram que a mídia não o permitiria jamais. A população, mesmo as pessoas mais simples, não é passiva e inventa formas de resistência contra as tentativas de manipulação. É um jogo. Perde-se e ganha-se. A teoria crítica julga que a publicidade e a mídia enganam os seus destinatários. Estes, pontualmente, resistem, deformam, desviam as mensagens.

Guy Debord, em A Sociedade do espetáculo, considerou a comunicação, em termos de mídia, como contemplação, na medida em que o telespectador viveria por procuração, graças a outros, graças às celebridades que encarnariam os seus sonhos. Essa é uma posição agora insustentável. De certa maneira, Jean Baudrillard também se encontra nesse universo de análise. Há uma herança marxista que aproxima os dois. Baudrillard é brilhante. Debord, cuja importância foi indiscutível, enraizou-se mais pela forma que pelo conteúdo. Baudrillard e Debord escrevem de uma forma que força a refletir. São agudos, provocativos, polêmicos.

Ora, Debord, contra o conformismo lógico atual, fustigou o pensamento da sua época. Levou a crítica da contemplação, numa lógica hegeliano-marxista, às últimas conseqüências. No entender dele, haveria uma realidade tangível, positiva, positivista, passível de controle. Caberia ser senhor da sua vida. Pierre Bourdieu pensava da mesma forma. Debord buscou esse domínio da própria vida até o suicídio. Numa perspectiva social, contudo, isso significa tomar o controle, administrar racionalmente o mundo, passar da contemplação à ação. É mais complicado: a realidade não se resume à realidade. Existe algo que se pode chamar de surrealismo, de sobre-realidade. Em outras palavras, existe ação na contemplação, resistência na passividade, astúcia na reserva, um estilo de vida na negociação com o que é. Debord ainda estava na lógica do deverser. A comunicação, hoje ainda mais, funciona no registro do aqui e agora.

Isso não impede nenhuma transformação do mundo, mas desconfia de todos os projetos totalizantes de transformação do mundo. A comunicação é sempre fragmentada, negociada, jogada, investida de emoções e de sentimentos, articulada entre partes que ora se opõem, ora se complementam. Reduzi-la à manipulação significa excluir a maior parte do fenômeno do campo da reflexão e da pesquisa .

Nota

* Reflexão concebida dialogicamente, a partir de proposições baseadas na obra de Michel Maffesoli, por Juremir Machado da Silva, que também traduziu o texto. 